\title{
PENGARUH SISTEM OLAH TANAH DAN PEMUPUKAN NITROGEN JANGKA PANJANG TERHADAP RESPIRASI RIZOSFER DAN NON RIZOSFER PERTANAMAN JAGUNG (Zea mays $\mathbf{L}$.)
}

\author{
Erwinda Meriko, Muhajir Utomo \& Henrie Buchari \\ Jurusan Agroteknologi, Fakultas Pertanian, Universitas Lampung \\ Jl. Prof. Soemantri Brodjonegoro, No. 1, Bandar Lampung 35145 \\ E-mail :Erwindameriko@ymail.com
}

\begin{abstract}
ABSTRAK
Kehilangan karbon di sektor pertanian disebabkan oleh cara praktik budidaya yang tidak berkelanjutan. Penlitian ini bertujuan untuk mengetahui pengaruh sistem tanpa olah tanah dan pemupukan nitrogen terhadap respirasi rizosfer dan non rizosfer. Penelitian ini dilakukan dengan menggunakan Rancangan Acak Kelompok (RAK) dan disusun scara faktorial dengan 4 ulangan. Faktor pertama adalah sistem olah olah tanah $(\mathrm{T})$ yaitu $\mathrm{T}_{0}=\operatorname{tanpa}$ olah tanah, $\mathrm{T}_{1}=$ olah tanah intensif, faktor kedua adalah dosis pupuk Nitrogen $(\mathrm{N})$, yaitu $\mathrm{N}_{0}=0 \mathrm{~kg} \mathrm{~N} \mathrm{ha}^{-1}, \mathrm{~N}_{1}=100 \mathrm{~kg} \mathrm{~N} \mathrm{ha}^{-1}$. Pengamatan dilakukan pada 2 tempat yaitu pada rizosfer dan tanah yang dibatasi oleh paralon yang disebut sebagai non rizosfer yang dilakukan pada -7, 2, 9 hari setelah olah tanah (HSO). Homogenitas ragam diuji dengan uji Bartlett dan additifitas data diuji dengan uji Tukey. Apabila asumsi terpenuhi data dianalisis dengan sidik ragam dan dilanjutkan uji perbedaan nilai tengah menggunakan Uji Beda Nyata Jujur (BNJ) pada taraf 5\%. Hasil penelitian menunjukkan bahwa respirasi rizosfer dan non rizosfer pada sistem tanpa olah tanah lebih rendah dari sistem olah tanah intensif dan respirasi rizosfer pada pemupukan $100 \mathrm{~kg} \mathrm{~N} \mathrm{ha}^{-1}$ lebih tinggi dari pemupukan $0 \mathrm{~kg} \mathrm{~N} \mathrm{ha}^{-1}$. Interaksi pada respirasi non rizosfer antara sistem olah tanah dan pemupukan $\mathrm{N}$ terjadi pada -7 dan $2 \mathrm{HSO}$.
\end{abstract}

Kata kunci : Olah tanah konservasi, respirasi rizosfer, respirasi non rizosfer

\section{PENDAHULUAN}

Kehilangan karbon di sektor pertanian disebabkan oleh cara praktik budidaya yang tidak berkelanjutan. Pertanian dengan olah tanah intensif di lahan kering merusak agregat tanah sehingga partikel-partikel tanah menjadi lepas dan karbon tanah hilang terbawa erosi, dan memacu oksidasi bahan organik tanah sehingga menurunkan cadangan karbon tanah dan meningkatkan emisi gas $\mathrm{CO}_{2}$ ( Utomo, 2004 ).

Aktivitas sektor pertanian menyumbang emisi gas rumah kaca (GRK) anthropogenik dalam pemanasan global sebesar 23\%, dan $90 \%$ nya berasal dari pertanian daerah tropik (Houghtoun, 1995). Jika keadaan ini terus berlanjut, dikhawatirkan bukan hanya akan meningkatkan pemanasan global, tetapi juga akan menurunkan ketahanan pangan nasional. Hal ini berdampak negatif terutama pada bidang pertanian. Diantaranya penurunan produksi tanaman pangan yang berakibat peningkatan resiko kekurangan pangan. Serta perubahan pola distribusi hewan dan serangga sebagai agen pembawa penyakit tanaman. Oleh karena itu, diperlukan pertanian alternatif yang mampu menjawab permasalahan tersebut. Dengan memanfaatkan residu tanaman dan mengurangi pengolahan tanah, olah tanah konservasi (OTK) mempunyai potensi untuk mengurangi pemanasan global melalui penyerapan $\mathrm{C}$ ke dalam tanah dan pengurangan emisi $\mathrm{CO}_{2}$ (Tjitrosemito, 2005).

Hasil penelitian tahun sebelumnya (tahun ke-22), sistem OTK mampu secara konsisten mengurangi emisi gas $\mathrm{CO}_{2}$ secara signifikan dan meningkatkan penyerapan $\mathrm{C}$ pada tanaman dan gulma lebih tinggi dibanding OTI, tetapi belum nyata dalam meningkatkan C tanah (Utomo, Henri dan Banuwa, 2010). Penelitian ini bertujuan untuk mengetahui pengaruh sistem tanpa olah tanah dan pemupukan $\mathrm{N}$ terhadap respirasi non rizosfer dan rizosfer pada lahan pertanaman jagung.

\section{BAHAN DAN METODE}

Penelitian ini dilaksanakan pada bulan Desember 2012 musim ke-43 sampai dengan bulan April 2013 di lahan Politeknik Negeri Lampung. Analisis tanah dilakukan di Laboratorium Jurusan Ilmu Tanah Fakultas Pertanian Universitas Lampung. Penelitian ini dirancang dalam Rancangan Acak Kelompok (RAK) dan disusun secara faktorial 4 ulangan. Faktor pertama dalam penelitian ini adalah perlakuan sistem olah tanah $(\mathrm{T})$ yaitu $\mathrm{T}_{0}=$ tanpa olah tanah, dan $\mathrm{T}_{1}=$ olah tanah intensif dan faktor kedua adalah pemupukan nitrogen $(\mathrm{N})$ yaitu $\mathrm{N}_{0}$ 
$=0 \mathrm{~kg} \mathrm{~N} \mathrm{ha}^{-1}$ dan $\mathrm{N}_{1}=100 \mathrm{~kg} \mathrm{~N} \mathrm{ha}^{-1}$. Data yang diperoleh diuji homogenitasnya dengan uji Barlet dan aditifitasnya dengan Uji Tukey. Apabila asumsi terpenuhi data dianalisis dengan sidik ragam dan dilanjutkan dengan Uji BNJ 5\%.

Sampel tanah diambil dari daerah perakaran tanaman jagung yang disebut sebagai respirasi rizosfer dan tanah yang dibatasi paralon yang disebut sebagai daerah non rizosfer. Respirasi rizosfer diambil di sekitar perakaran tanaman jagung atau di sela-sela barisan pada 9 HSO. Respirasi non rizosfer diukur langsung dilapangan dengan metode Verstraete (Anas, 1989; Stotzky, 1965 dalam A.L, Page dkk., 1982). Respirasi non rizosfer diukur dengan cara membenamkan paralon sekitar 20-30 cm kedalam tanah kemudian menutup permukaan tanah dengan toples yang telah diketahui volumenya yang di dalamnya berisikan botol film

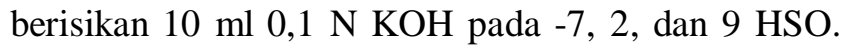
Agar tidak terjadi kebocoran, toples dibenam kedalam tanah 2-3 cm. seperti yang pertama, toples kedua sebagai blanko dimana botol film berisikan $10 \mathrm{ml} 0,1 \mathrm{~N}$ $\mathrm{KOH}$ juga dibenamkan, akan tetapi permukaan tanah dilapisi plastik terlebih dahulu sehingga tidak menangkap $\mathrm{CO}_{2}$ dari tanah. Perlakuan tersebut dilakukan pagi dan sore selama 2 jam pada tiap-tiap plot perlakuan.

Pada akhir masa inkubasi kuantitas $\mathrm{C}-\mathrm{CO}_{2}$ yang dihasilkan ditentukan dengan cara dititrasi. Dua tetes fonolptalin ditambahkan ke dalam gelas beaker yang berisi $\mathrm{KOH}$ sampel, kemudian dititrasi dengan $\mathrm{HCl}$ sampai warna merah menjadi hilang (volume yang diperlukan dicatat). Kemudian ditambahkan 2 tetes metal orange dan dititrasi kembali dengan $\mathrm{HCl}$ sampai warna kuning (orange) berubah menjadi merah muda pink (pink). Jumlah $\mathrm{HCl}$ yang digunakan pada tahap kedua titrasi berhubungan langsung dengan jumlah $\mathrm{CO}_{2}$ yang difiksasi. Cara yang sama juga dilakukan dengan toples tanpa tanah sebagai kontrol $\mathrm{CO}_{2}$.

Jumlah $\mathrm{CO}_{2}$ total dapat dihitung dengan menggunakan formula:

$$
\mathrm{C}-\mathrm{CO}_{2}=\frac{(\mathrm{a}-\mathrm{c}) \times \mathrm{t} \times 12}{\mathrm{~T} \times \mathrm{x} \mathrm{r}^{2}}
$$

Jumlah $\mathrm{CO}_{2}$ dari tanah dapat dihitung dengan menggunakan formula:

$$
\mathrm{C}-\mathrm{CO}_{2}=\frac{(\mathrm{b}-\mathrm{c}) \times \mathrm{t} \times 12}{\mathrm{~T} \times \partial \times \mathrm{r}^{2}}
$$

Untuk jumlah $\mathrm{CO}_{2}$ dari rizosfer dihitung dari respirasi total - respirasi non rizosfer.

Keterangan :

$\mathrm{C}-\mathrm{CO}_{2}=\mathrm{mg} \mathrm{jam}^{-1} \mathrm{~m}^{-2}$

$\mathrm{a}=\mathrm{ml} \mathrm{HCl}$ untuk respirasi total (setelah $\mathrm{d}$ ditambahkan metil orange )

$\mathrm{b} \quad=\mathrm{ml} \mathrm{HCl}$ untuk respirasi non rizosfer (setelah ditambahkan metil orange )

c $=\mathrm{ml} \mathrm{HCl} \mathrm{untuk} \mathrm{kontrol} \mathrm{(setelah} \mathrm{ditambahkan}$ metil orange )

$\begin{array}{ll}\mathrm{t} & =\text { normalitas } \mathrm{HCl} \\ \mathrm{T} & =\text { waktu pengukuran }(\mathrm{jam})\end{array}$

$\mathrm{R} \quad=$ jari jari tabung toples $(\mathrm{m})$

\section{HASIL DAN PEMBAHASAN}

Respirasi Rizosfer. Hasil ringkasan analisis ragam respirasi rizosfer disajikan dalam Tabel 1. Pada 9 HSO, perlakuan olah tanah menunjukkan pengaruh nyata terhadap respirasi rizosfer. Hal ini disebabkan pada $9 \mathrm{HSO}$ masih terdapat pengaruh pengolahan tanah dan aktivitas organisme dalam tanah serta adanya aktivitas perakaran tanaman jagung.

Pada pengamatan $9 \mathrm{HSO}$, respirasi rizosfer pada olah tanah intensif lebih tinggi daripada tanpa olah tanah (Tabel 2). Hal ini disebabkan tanah masih dipengaruhi oleh pengolahan tanah yang menyebabkan oksigen dapat masuk dengan mudah ke dalam tanah, sehingga sesuai dengan lingkungan yang dikehendaki organisme tanah untuk dapat menghancurkan bahan organik dalam

Tabel 1. Ringkasan analisis ragam respirasi rizosfer akibat pengaruh sistem olah tanah dan pemupukan $\mathrm{N}$ jangka panjang pada pertanaman jagung.

\begin{tabular}{cc}
\hline Sumber Keragaman & 9 HSO \\
\hline $\mathrm{T}$ & $*$ \\
$\mathrm{~N}$ & tn \\
$\mathrm{TN}$ & tn
\end{tabular}

Keterangan: $\mathrm{T}=$ sistem olah tanah, $\mathrm{N}=$ pemupukan nitrogen, $\mathrm{TN}=$ interaksi sistem olah tanah dan pemupukan nitrogen, $*$ = nyata, $\mathrm{tn}=$ tidak nyata, $\mathrm{HSO}=$ hari setelah olah tanah. 
membantu proses dekomposisi bahan organik (Sarief, 1985) dan mulainya aktivitas perakaran tanaman jagung.

Dilihat dari kondisi sistem tanpa olah tanah, seharusnya respirasi rizosfer pada sistem tanpa olah tanah lebih tinggi dibandingkan dengan sistem olah tanah intensif. Pada sistem TOT, suhu dan kelembaban tanah terjaga dan mulsa yang ada pada permukaan tanah akan menyebabkan kandungan bahan organik tanah tinggi. Hal ini mendukung aktivitas organisme dalam tanah pada sistem TOT. Namun, kondisi ini tidak didukung oleh struktur tanah pada sistem TOT yang semakin padat yang menyebabkan terbatasnya aktivitas oganisme dalam merombak bahan organik.
Respirasi Non Rizosfer. Hasil ringkasan analisis ragam untuk pengaruh sistem olah tanah dan pemupukan $\mathrm{N}$ terhadap respirasi non rizosfer disajikan dalam Tabel 3. Hasil analisis ragam tersebut menunjukkan bahwa perlakuan yang diberikan berpengaruh terhadap respirasi non rizosfer sampai pengamatan $2 \mathrm{HSO}$, kecuali perlakuan nitrogen. Perlakuan sistem olah tanah berpengaruh nyata diduga karena respirasi non rizosfer tersebut masih dipengaruhi oleh pengolahan tanah pada perlakuan Olah Tanah Konservasi (OTK) yang dilakukan pada penelitian musim sebelumnya yaitu pada akhir tahun 2011.

Tabel 2. Pengaruh sistem olah tanah dan pemupukan nitrogen jangka panjang terhadap respirasi pada rizosfer pertanaman jagung 9 HSO.

\begin{tabular}{cc}
\hline Perlakuan & Rata-rata respirasi $\left(\mathrm{kg} \mathrm{C}^{-} \mathrm{CO}_{2}\right.$ hari $^{-1}$ ha $\left.^{-1}\right)$ \\
\hline $\mathrm{T}_{0}$ & $6,1 \mathrm{a}$ \\
$\mathrm{T}_{1}$ & $11,8 \mathrm{~b}$ \\
\hline
\end{tabular}

BNJ 0,05

1,6

Keterangan :Angka yang diikuti oleh huruf yang sama tidak berbeda nyata dengan uji BNJ pada taraf nyata 5\%, $\mathrm{T}_{0}=$ TOT, $\mathrm{T}_{1}=$ OTI $, \mathrm{N}_{0}=0 \mathrm{~kg} \mathrm{~N} \mathrm{ha}{ }^{-1}, \mathrm{~N}_{1}=100 \mathrm{~kg} \mathrm{~N} \mathrm{ha}^{-1}$.

Tabel 3. Ringkasan analisis ragam respirasi non rizosfer akibat pengaruh sistem olah tanah dan pemupukan $\mathrm{N}$ jangka panjang pada pertanaman jagung.

\begin{tabular}{cccc}
\hline $\mathrm{SK}$ & $-7 \mathrm{HSO}$ & $2 \mathrm{HSO}$ & $9 \mathrm{HSO}$ \\
\hline $\mathrm{T}$ & $*$ & $*$ & tn \\
$\mathrm{N}$ & tn & tn & tn \\
$\mathrm{TN}$ & $*$ & $*$ & tn \\
\hline
\end{tabular}

Keterangan: $\mathrm{N}=$ Pemupukan Nitrogen, $\mathrm{T}=$ Olah Tanah, ${ }^{*}=$ nyata, $\mathrm{tn}=$ tidak nyata, $\mathrm{HSO}=$ hari setelah olah tanah

Tabel 4. Pengaruh interaksi sistem olah tanah dan pemupukan nitrogen jangka panjang terhadap respirasi non rizosfer pertanaman jagung -7 HSO.

\begin{tabular}{cccc}
\hline \multirow{2}{*}{ Sistem Olah Tanah } & \multicolumn{2}{c}{ Pemupukan Nitrogen } & \multirow{2}{*}{ BNJ 0,05 } \\
\cline { 2 - 3 } & $0 \mathrm{~kg} \mathrm{~N} \mathrm{ha}^{-1}$ & $(9,1) 3,1 \mathrm{a}$ \\
Tanpa Olah Tanah (TOT) & $(9,7) 3,2 \mathrm{a}$ & $\mathrm{A}$ & \\
& $\mathrm{A}$ & $(15,1) 4,0 \mathrm{~b}$ & 0,4 \\
Olah Tanah Intensif (OTI) & $(12,6) 3,6 \mathrm{a}$ & $\mathrm{B}$ & \\
& $\mathrm{B}$ & 0,4 & \\
\hline
\end{tabular}

BNJ 0,05 0,4

Keterangan : Angka yang diikuti oleh huruf yang sama tidak berbeda nyata dengan uji BNJ pada taraf nyata 5\%. Huruf kecil merupakan notasi untuk membedakan pada baris yang sama. Huruf kapital merupakan notasi untuk membedakan pada kolom yang sama. $(\mathrm{x})=$ angka di dalam kurung adalah angka asli. $\mathrm{T}_{0}$ $=$ TOT, $\mathrm{T}_{1}=$ OTI $, \mathrm{N}_{0}=0 \mathrm{~kg} \mathrm{~N} \mathrm{ha}^{-1}, \mathrm{~N}_{1}=100 \mathrm{~kg} \mathrm{~N} \mathrm{ha}^{-1}$. 
Tabel 5. Pengaruh interaksi sistem olah tanah dan pemupukan nitrogen jangka panjang terhadap respirasi rizosfer pada pertanaman jagung 2 HSO.

\begin{tabular}{cccc}
\hline \multirow{2}{*}{ Sistem Olah Tanah } & \multicolumn{2}{c}{ Pempukan Nitrogen } & \multirow{2}{*}{ BNJ 0,05 } \\
\cline { 2 - 3 } & $0 \mathrm{~kg} \mathrm{~N} \mathrm{ha}^{-1}$ & $100 \mathrm{~kg} \mathrm{Nha}^{-1}$ & \\
\hline Tanpa Olah Tanah (TOT) & $10,5 \mathrm{~b}$ & $9,7 \mathrm{a}$ & 1,1 \\
& $\mathrm{~A}$ & $\mathrm{~A}$ & \\
Olah Tanah Intensif (OTI) & $14,5 \mathrm{a}$ & $\mathrm{B}, 1 \mathrm{a}$ & \\
& $\mathrm{B}$ & \\
\hline BNJ 0,05 & \multicolumn{3}{c}{1,1} \\
\hline
\end{tabular}

Keterangan : Angka yang diikuti oleh huruf yang sama tidak berbeda nyata dengan uji BNJ pada taraf nyata 5\%. Huruf kecil merupakan notasi untuk membedakan pada baris yang sama. Huruf kapital merupakan notasi untuk membedakan pada kolom yang sama. $\mathrm{T}_{0}=\mathrm{TOT}, \mathrm{T}_{1}=\mathrm{OTI}, \mathrm{N}_{0}=0 \mathrm{~kg} \mathrm{~N} \mathrm{ha}{ }^{-1}, \mathrm{~N}_{1}=100$ $\mathrm{kg} \mathrm{N} \mathrm{ha} a^{-1}$.

Pada pengamatan -7 HSO (Tabel 4) terjadi interaksi antara pengolahan tanah dan pemupukan $\mathrm{N}$. Kombinasi perlakuan yang menghasilkan respirasi non rizosfer tertinggi adalah pada sistem olah tanah intensif dan pemupukan $100 \mathrm{~kg} \mathrm{~N}^{-1}$ tetapi tidak berbeda dengan kombinasi tanpa pemupukan nitrogen. Hal ini disebabkan tanah yang diolah secara intensif memiliki ruang pori yang besar sehingga tanah memiliki aerasi yang baik dan menyebabkan pertukaran gas menjadi baik. Selain itu, dengan pemberian $100 \mathrm{~kg} \mathrm{~N} \mathrm{ha-1}$ semakin menambah unsur hara dalam tanah dan menyebabkan aktivitas organisme dalam merombak bahan organik semakin tinggi. Oleh karena itu, kombinasi perlakuan sistem olah tanah intensif dan

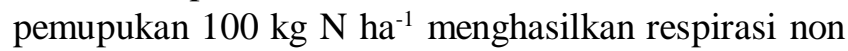
rizosfer tertinggi.

\section{KESIMPULAN}

Hasil penelitian menunjukkan bahwa respirasi rizosfer dan non rizosfer pada sistem tanpa olah tanah lebih rendah dari sistem olah tanah intensif dan respirasi rizosfer pada pemupukan $100 \mathrm{~kg} \mathrm{~N}^{-1} \mathrm{a}^{-1}$ lebih tinggi dari pemupukan $0 \mathrm{~kg} \mathrm{~N} \mathrm{ha}^{-1}$. Interaksi pada respirasi non rizosfer antara sistem olah tanah dan pemupukan $\mathrm{N}$ terjadi pada -7 dan 2 HSO.

\section{DAFTAR PUSTAKA}

Anas, I. 1989. Biologi Tanah dalam Praktek. Departemen Pendidikan danKebudayaan Direktorat Jendral Pendidikan Tinggi Pusat antar Universitas Bioteknologi. Institut Pertanian Bogor. $161 \mathrm{hlm}$.

Houghton, R.A. 1995. Change in the storage of terrestrial carbon since 1850. In R. Lal, J. Kimbal, E. Levine and B.A.Stewart(eds) p. 45-65. Soils and Global Change.CRC Press.Boca Raton,FL.

Sarief, E. S. 1985. Ilmu Tanah Pertanian. Pustaka Buana. Bandung. $157 \mathrm{hlm}$.

Tjitrosesemito, S. 2005. Olah Tanah Konservasi. Prospek dan Tantangan Pertanian Indonesia di Era Globalisasi. 35 Tahun PT Agricon. PT Agricon. 